\title{
Authority Control: Sharing Cataloguing Experiences Practiced at the Library of Open University of Sri Lanka
}

\author{
Damayanthi Gunasekera ${ }^{1}$
}

\begin{abstract}
The article discusses the nature and importance of subject analysis and the retrieval tools used in subject authority control at the Open University of Sri Lanka (OUSL) library. The article documents the cataloguing practices used at OUSL library and how objectives of the catalogue as mentioned by Cutter are achieved by creating an efficient catalogue. Further, how authority control is done at the OUSL library to create an efficient catalogue which is needed for an efficient retrieval of information is also analyzed. The article explains further, the three types of authority files that are maintained by the OUSL library and the importance of maintaining authority control in digital environment. In addition to that, how cataloguing and classification are practiced to keep the consistency of the catalogue is also discussed. The purpose of the article is to inform others how OUSL has developed and maintained the authority lists with the aim of effective retrieval. The problem that influenced the author to write the article is that there are no proper guidelines available nationally to be used by the professionals. Each institution/country is responsible for authority headings for its own personal and corporate authors. IFLA emphasizes that national authority lists should be available in each country for everyone to use but it is not available in Sri Lanka. This article will be an eye opener for the LIS professionals to think about such as important attempt. The objective of the article is to share OUSL library practices among LIS professionals and to inform the value of maintaining authority control in digital environment. Action research method was applied to conduct the study to achieve the objective. Archival data and author experiences were used to write the article. Survey and observation methods were used to collect archival data. Accordingly, findings were presented with examples. Further, included in the discussion are the requirements for effective subject retrieval from OPAC, bibliographic databases, full text systems, digital archives and the Internet. It attempts to project the nature of subject analysis systems requirements into the future and to draw some conclusions about what new information professionals should be taught and what skills they need to acquire to develop and operate subject analysis systems into the next century. Finally, it challenges information professionals to seize the opportunity and to take responsibility for subject analysis in retrieval of information now and into the future.
\end{abstract}

Keywords: Authority control, Authority file maintenance, Cataloguing practices, Metadata creation

\footnotetext{
${ }^{1}$ Senior Assistant Librarian, The Open University of Sri Lanka, E-mail: hpsgun@ou.ac.lk, iD https://orcid.org/0000-0002-0206-1857
} 


\section{Introduction}

Cataloguing is the process of creating metadata representing information resources, such as books, reports, manuscripts, sound recordings, moving images, e-materials etc. Cataloguing provides bibliographic information that describes resources, typically through the creation of bibliographic records. The cataloguing process results in the production of a library catalogue.

A catalogue is a key to collection of a library or group of libraries. The purpose of the catalogue is inventorying and retrieval of information. The objective of a library catalogue is to locate materials efficiently, for which an efficient catalogue is needed. An efficient catalogue can be created through Authority Control (AC).

A basic definition of $\mathrm{AC}$ is the process used to maintain consistency in access points and the process of showing the relationship among names, subjects and works. Further, in library science, authority control is a process that organizes bibliographic information (for example in library catalogue) by using a single, distinct spelling of a name (heading) or a numeric identifier for each topic. The word authority in authority control derives from the idea that the names of people, places, things, and concepts are authorized; they are established in one particular form. These one-of-a-kind headings or identifiers are applied consistently throughout the catalogue which make use of the respective authority file, and are applied for other methods of organizing data such as linkages and cross references.

The definition for the AC given in the ANE's Dictionary is as follows:

'the procedures by which consistency of form is maintained in the headings (names, uniform titles, series titles, and subjects) used in a library catalogue or file of bibliographic records, through the application of an authoritative list called an authority file to new items as they are added to the collection'.(ANE's encyclopedic dictionary of LIS, 2006,p.75)

According to American Library Association

"AC is one of the librarian's most important bibliographical tools - is also one of the most overlooked and under-worked devices in library land. Automation is however, bringing it to the forefront as one of the most important cataloguing and searching tool that is required to establish and maintain order in our processing and user worlds. The advent of on-line terminals and other developments have brought the realization that we cannot hide incorrect entries in modern easily accessible public catalogues. AC is a must if chaos is to be kept out of our modern bibliographical and searching systems" (American Library Association, 1979, p. 45) 


\section{The OUSL Library}

The Open University of Sri Lanka (OUSL) is the only national university which offers study programmes through Open and Distance Learning (ODL) mode in Sri Lanka.

Due to the nature of its teaching methodology and infrastructure facilities, the OUSL is serving a large distance learning population scattered throughout the country. Distance learners often use the library for their various needs. They expect a comprehensive collection of resources, reference facilities, staff support and friendly and comfortable study environment within the library (Library Hand Book, 2014). Therefore, it is a duty of the library to organize information according to the user needs and expectations for their study requirements.

\section{Cataloguing Practices at the Library}

The OUSL main library has a fully automated library management system using 'Koha' database. Library materials are ordered using the database. When new materials arrive bibliographic information and subject key words are entered into the MARC21 format worksheet by the cataloguers. AARC2, RDA, LCSH and DDC $23^{\text {rd }}$ edition are the standards used for cataloguing and classification of materials. General objective of organizing information through cataloguing and classification is to disseminate information to users efficiently. Proper dissemination can be done through the proper organization of information. Proper organization of information can be done using the authority files. Three types of authority files, namely 'Name', 'Title/Series' and 'Key word' are maintained by the OUSL library.

The OUSL library does not follow copy cataloguing although pre-existing data sources are freely available for copying. The main reason is that the given class number and the key words for a particular material are different to our necessity and pattern of assigning key words. According to Cutter, the most important consideration in the cataloguing of library materials is "the best interest of the user". He calls this principle as "the convenience of the public" (Chan, 2016). On this principle, the distance learner's usage at OUSL library becomes an important determining factor in selecting the terms and the forms of subject headings. The OUSL cataloguing team knows their user/reader. Accordingly, key indexing terms are used. Therefore, mixed method of cataloguing is used to create more convenient access points. The reason is that access points serve the dual functions of location and collocation of information. Finally, after examining the entry whether all bibliographic information is correctly entered to the database as recorded in authority file records, materials are placed on the shelves. Lending and returning are also done using the barcode machines.

\section{Literature Review}

A catalogue is a key to the collection of a library or group of libraries. It represents the holdings of the particular institution or library network or particular location. 
According to Seymour Lubetzky (1953):

'to enable the user of the catalogue to determine readily, whether or not the library has a book he wants...the second objective is to retrieve to the user of the catalogue, under one form of the author's name, what works the library has by a given author and what editions or translations of a given work'

In libraries, metadata creation is called cataloguing. Cataloguing is a subset of the larger field called information organization. It can be defined as:

"the process of creating metadata for resources by describing a resource, choosing name and title access points, conducting subject analysis, assigning subject headings and classification numbers, and maintaining the system through which the cataloguing data is made available." Joudrey, Taylor and Miller (2015)

Metadata assists users to find, select, and obtain the resources in the collection.

Preparing an index by creating metadata to a book or assigning indexing terms to documents involves the task of subject analysis. Subject analysis can be defined as "the intellectual or automated process by which the subjects of a document are analyzed for subsequent expression in the form of subject data".

The definition extracted from a reliable source, ANE's encyclopedic dictionary of LIS (2006) describes subject analysis as:

"examination of a bibliographic item by a trained subject specialist to determine the most specific subject heading(s) or descriptor(s) that fully describe its content, to serve in the bibliographic record as access points in a subject search of a library catalogue, index, abstracting service or bibliographic database".

Further, it is a process of ascertaining the 'aboutness' of a document by describing its topic, the discipline in which the topic is treated, and the form of the document.

The discipline is an area of knowledge. It is the context in which any subject is treated.

The form is what the document is rather than what it contains. The form is related to organization of the intellectual content, presentation of the subject content and physical form of the material. When the compilation of intellectual content is considered the analyzer or cataloguer has to analyze whether it is a text book, autobiography, fiction, drama or historical review etc. The presentation of the subject content should be studied to consider whether it has statistical compilations, questions and answers and so on. The physical form should be examined when analyzing the material to decide whether it could be categorized as a book, e-book, map or video, 
etc. because you have to describe the format (General Material Description=GMD) and to assign key words for the entry in the following way.

\section{E.g. - Film (GMD) \\ Book (GMD) \\ Proceeding (GMD)}

\section{Steps in Subject Analysis}

Basically, subject analysis of a particular work or document involves three steps. They are:

- Determining the overall subject content of the item being cataloged,

- Identifying multiple subjects and/or subject aspects and interrelationships,

- Representing both of these concerns in the language of the controlled vocabulary at hand.

Subject analysis is supported by the subject headings introduced by the Library of Congress (LC). LCSH is the subject heading list which makes more sense to libraries to simply use their own subject headings, introduced by the LC.

It is advisable to know the purpose of controlled vocabulary and its relation with subject analysis.

There are two methods of generating key words after understanding of the subject of particular work. One method is assigning key word by using natural language and the other method is that key words should be assigned by the subject selections using a Thesaurus, by doing that controlled vocabulary can be formed.

\section{Natural Language Usage}

There are many ways that a cataloguer could describe the subject matter of documents using natural language. A cataloguer could simply extract words from the document. The words can be selected from the content or abstract/summary. Uncontrolled key words can also be used by the cataloguer's own knowledge. That is, we use natural language to describe the subject of a material. However, these approaches will lead to inconsistency. Therefore, use of this method is not recommended. But many scholars have opinion that this method is more suitable than using controlled vocabulary. The reason given by them is that controlled vocabulary is not updated regularly while other formats are changed/updated rapidly. e.g., MARC format. However, if there are no terms available in the subject heading list, information organizers have to follow this method. 


\section{Controlled Vocabulary}

The use of a standardized subject language (LCSH, MeSh) to describe the contents of resources can be called as controlled vocabulary $(\mathrm{CV})$.

According to the Encyclopedia of Library and Information Science (2002) controlled vocabulary is defined as,

"A carefully selected list of words and phrases, the terms are chosen and organized by subject specialists. Terms can accurately describe what a given document is actually about in the documents."

In other words, it is describing the aboutness of resources using controlled language. When the vocabulary is controlled, subject cataloguing is more consistent. The main objective of $\mathrm{CV}$ is to promote the consistent representation and comprehensive searching of subject matter. Examples for controlled vocabularies are;

Art \& Architecture Thesaurus (AAT)

Thesaurus for Graphic Materials I: Subject Terms (TGMI)

Thesaurus of Geographic Names (TGN)

Examples for Subject heading lists are;

Library of Congress Subject Headings (LCSH)

Sears List of Subject Headings

Medical Subject Headings (MeSH)

In addition, a classification notation is chosen from whatever the classification scheme is used by the library, mostly the Dewey decimal classification to prepare the authority files entries.

\section{Authority Control}

The word 'authority' in authority control derives from the idea that the names of people, places, things, and concepts are authorized; they are established in one particular form. These one-of-a-kind headings or identifiers are applied consistently throughout the catalogues which make use of the respective authority file, and are applied for other methods of organizing data such as linkages and cross references.

The definition for the Authority Control, given in the ANE's Dictionary (2006) is that

'the procedures by which consistency of form is maintained in the headings (names, uniform titles, series titles, and subjects) used in a library catalogue or file of bibliographic records, through the application of an authoritative list called an authority file to new items as they are added to the collection'.

Accordingly, Authority File (AF) is a record of the connect forms of names, series, subject or uniform titles used in the catalogue. 


\section{Different Authority Files}

A customary way of enforcing authority control in a bibliographic catalogue is to set up a separate index of authority records which relates to and governs the headings used in the main catalogue. This separate index is often referred to as an "Authority File (AF)." It contains an indexable record of all decisions made by cataloguers in a given library, which cataloguers consult when making or revising decisions about headings. As a result, the records contain documentation about sources used to establish a particular preferred heading, and may contain information discovered while researching the heading which may be useful.

An authority file can be defined as:

a list of the authoritative terms of the headings used in a library catalogue or file of bibliographic records, maintain to ensure that the headings are applied consistently as new items are added to the collection, separate authority files are usually maintained for names, uniform titles, series titles and subjects. All the references made to and form a given heading are also included in the authority file. (ANE's encyclopedic dictionary of LIS, 2006, p.75)

An authority record includes three basic components and they are 1) Headings, 2) Cross references, and 3) Notes.

\section{Virtual Authority File}

There are virtual authority files available in different organizations. Catalogers can create links between pre-existing data sources, rather than spending time to create new authority records. Currently authority control projects have become much more feasible and provide such "linkable" data sources.

Virtual International Authority File is a collaborative attempt to provide a single heading for a particular subject. It is a way to standardize information from different authority files around the world such as the Integrated Authority File (IAF), maintained and used cooperatively by many libraries in German-speaking countries and the United States Library of Congress. The International Standard Name Identifier (ISNI), LC/NAF, Open Researcher and Contributor ID (ORCID), Scopus, Virtual International Authority File (VIAF) and VIVO are examples of such files.

Each country is responsible for authority headings for its own personal and corporate authors. National authority lists are available in each country for everyone to use. E.g. HKCAN, Japan MARC Authority file, KOR MARC. Authority lists related to each country are available in IFLA website but there is no list available for Sri Lanka. It is worth to mention that Name authority file for Sri Lankan authors was prepared by the National Library and Documentation Services Board in 2005. 


\section{Statement of Problem}

It is observed that different libraries follow different patterns on authority control. It is also observed that different rules and old methods are followed for authority control. Some are not aware about subject analysis and how to create effective catalogue through authority control. Hence some libraries are not doing authority control and subject analysis when creating metadata. Therefore, the main problem is whether the method followed by the OUSL library is correct or not as there is no proper standard pattern of creating authority control among the libraries. The main purpose of the article is to share best practices followed by OUSL with other professionals who are engaged in the organization of information.

\section{Research Objectives}

The main objective of this article is to share knowledge on subject analysis and best practices with other professionals in the field.

The other objectives are,

to inform how important is the authority control in organizing information,

to make aware how Authority File could be maintained

The following three (03) research questions were formulated for seeking solution for that question.

\section{Research Questions}

What are the best practices followed by OUSL main library in authority control?

How does OUSL create metadata analyzing subjects?

How does OUSL maintain authority files?

\section{Research Methodology}

Action research method was engaged to conduct this process as it is the most suitable method to find out answers for the above questions. Because action research is a reflective process of progressive problem-solving led by individuals working with others in teams or as part of a "community of practice" to improve the way they address issues and solve problems. There are two types of action research: participatory and practical. Denscombe (2010) writes that an action research strategy's purpose is to solve a particular problem and to produce guidelines for effective practices. Action research simultaneously assists in practical problemsolving and expands scientific knowledge, as well as enhances the competencies of the respective actors. Further, out of three purposes of action research two purposes that are given below are most applicable to this study:

- Building the reflective practitioner

- Building professional cultures 
Reflective practices support to improve process of cataloguing and creation of metadata through subject analysis and they help to create a skillful professional to the field. Further, as introduced by McNiff (2002) action research is an enquiry by the self into the self which can be called 'a kind of self-reflective practice'. Therefore knowledge generated through such inquiry would be widely acknowledged as a kind of knowledge which will support towards the development of individuals in the system. Further, there is clear empirical evidence to support the idea that individual inquiries into their own practice have influenced the quality of learning and action within the institutional setting. The article analyzes and describes the own professional role played by the professional librarians at OUSL. Therefore, action research method was applied.

\section{Data Collection Method}

Archival literature was used to collect data to write the article in addition to the author experiences. Descriptive and content analysis was done to present findings.

\section{Findings of the Study}

Maintenance of Authority Files at OUSL Library

Name Authority file

The OUSL library maintains the 'name' authority file which consists of records on pattern of writing the name of the contributors. Personal names of the authors and contributors are used as access points in catalogues and those names must be entered in a uniform, official form. Especially the OUSL library maintained Name Authority File which is used as different name components by the Sri Lankan authors. The object of the Name Authority File (NAF) is to ensure that all works by a single author will appear together. According to Lankage (Lankage, 1997, 2010) there are different name components of Sri Lankan laymen and Buddhist monk writers. Due to that maintaining NAF is very important.

Therefore, heading is recorded in NAF for the first time cataloguing as shown below.

Surname first as instructed in Anglo-American Cataloguing Rules (AACR2) and Resource Description and Access (RDA), rest of the name as same as appeared or mentioned in the work.

$$
\begin{array}{ll}
\text { E.g. } & \text { Wickramasinghe, Martin } \\
& \text { Suraweera, A.V. } \\
& \text { Wordsworth, W., 1770-1850 } \\
& \text { Woolf, Virginia, 1882-1941 } \\
& \text { Poe, Edgar Allen, 1809-1849 }
\end{array}
$$

Further, there are different name components of Sri Lankan laymen and Buddhist monk writers (Lankage $(1997,2010))$. Refer to the examples of writing same name in different ways. 

E.g.: 1. Dissanayaka
2. Thilakerathne
Dissanayake
Thilakeratne
Disanayaka
Tilakeratne

3. Mahida Tera

Ariyachana Thera

Buddhagosa Himi

Dharmasene Himi

In addition to that Sri Lankan Buddhist monks have honorifics such as Maha Thero, Maha nayake stavira, Yati, yatindu, etc. So decision recorded in the NAF by the OUSL library is 'use only the name, honorific and the name of the village where the monk was born, as heading in this way;

Ariyadhamma Tera, Nauyane

Soma Tera, Gangodawila

We have to use honorifics in some instances, such as 'Sri, Siri' given in names in this way as it is unavoidable in an entry as these honorifics are mentioned in the name of the Tera.

\section{E.g. Sri Rahula Tero, Totagamuwe, \\ Sri Sumangala Tero, Hikkaduwe.}

Writing pattern of names is stated in an entry in the AF as given above. However, other information such as class number for the particular time period and the key word made for the classification scheme is also mentioned in an entry and are filed in an authority file as given below; hence it is more useful for the cataloguer as well as for the other staff of the library.

E.g.

891.483

Wickramasinghe, Martin

Sinhalese fiction

821.6

Wordsworth, W. 1770-1850

English fiction $-18^{\text {th }}$ century 823.7

Edgar Allen 1809-1849

English fiction - Romantic period
891.482

Ediriweera, Sarachchandra

Sinhalese drama

823.9

Woolf, Virginia 1882-1941

English fiction - Modern period 823.8

Wilds, Oscar 1854-1900

English fiction $-17^{\text {th }}$ century

Further, the OUSL library uses clear instruction given by the DDC and LC Thesaurus to build key words for the Subject Authority File (SAF) when assigning key words to the entry. In addition to that other sources such as 'The Cambridge guide to English literature, Who's who' in different subjects are also used to clarify the time period of the author.

Although names of the Sri Lankan laymen authors have different name components as stated above, the name of the author is entered as appeared in the title page, if the 
work is in English language. If the work is in any other language, name appeared in the authority file is used as heading to keep the consistency of the catalogue to avoid the confusion since users/researchers may miss some information. In that way, Authority control is used by the OUSL library cataloguers to collocate materials that logically belong together but present themselves differently.

Suppose the name of the author is changed, for example a layman becomes a monk or vice versa, 'See reference' note is included to the manual AF while updating database giving 'note' in the MARC worksheet.

Therefore, the OUSL library maintains the Name Authority File as described above to keep the consistency for easy retrieval purpose of information from the collection.

\section{Title/Series Authority File}

Title, sub-title, alternative and parallel title of the work is written according to the AACR2 /RDA guidelines and authority records are used. Conference headings are also stated as instructed in the AACR2. The uniform title and series title headings are also recorded in the AF as follows,

An example for uniform title is:

The Tripitaka

The Bible

All works on Buddhism belongs to three 'pitak's' are arranged under the 'Tripitaka'. If the three 'pitaks' are separated as Vinayapitak, Suttapitaka or Abhidahammapitaka and they are classified under the same name and subject.

'The Bible' is another example for uniform title. All works related to Bible are classified under the title of Bible. New Testament, Old Testaments, etc. are catalogued under the subject heading 'The Bible' but heading is written as same as appeared in the title.

If it is a series, the title will have several volumes in different subjects. E.g: There are four volume sets of encyclopedia under the series of Distance Education. These four volumes are in four subject areas such as distance education (classification no. 374.), special education (370.9), higher education (378) and online education (374.26). According to these classification numbers, four volumes are shelved in four different places though they are under one series. If cataloguer wants to keep all volumes in one place it can be done by assigning general class number (374) for the whole set. The OUSL library follows the second method and all volumes are classified under the subject of series. The class number, 374 is for distance education and all volumes are given 374 class number and are kept in one place on the book shelf. Keeping one place is not useful for users as subjects are different. The solution given by the OUSL professionals is that subject related keywords are assigned to each 
entry for easy access. Later, AC records are updated and kept in one place giving classification numbers for the subject of the series title while the subject analysis is done separately.

Conference, meeting and workshops headings are given to the organizer of the event without giving the title as instructed by the AACR2 and RDA. The country name is given separated by a dot from the corporate names.

E.g. Sri Lanka. Ministry of Higher Education, Sri Lanka. Department of Health, Sri Lanka. Institute of Chemistry.

In this way, each controlled entry is described in an authority record in terms of its scope and usage, and such organization helps the library staff to maintain the catalogue and make it user-friendly.

\section{Subject Authority File}

Subject headings make more access points for a particular material. Cataloguer has to choose Subject headings which are indexed in the catalogue. Indexing makes a field searchable, or makes it an access point. How does one choose which fields to index? Cataloguer decision should be based on how users search for information. However, you can make any field in the database searchable. It does not mean that Subject analysis is the part of cataloguing that deals with the conceptual analysis of an item, what it is about, what form or format it is and translating that analysis into a particular subject heading system.

\section{E.g. Child development Economic conditions}

Class numbers represent subjects. Subject headings are created according to the class number.

370.72 Educational research

341-Internatioal law

There are two methods of creating subject headings. It can be done using natural language and vocabulary control. The OUSL main library practises both methods. Subject expertise and professional experience is needed to create subject heading using natural language. The practice of OUSL of creating AF is that each subject heading (each topic, main key word) assigned to the particular class number is recorded in a catalogue card. Those catalogue cards are arranged according to the classification number. This type of file, one card for each subject heading is used in the catalogue. If there are any references made to that subject, it is also recorded on the card. The file which records all decisions is called Subject AF (SAF). In such a manner OUSL library prepares subject AF. Every day it is developed by inserting new decisions. The maintenance is done by the experts editing existing cards when 
new class number and new key words are introduced. According to Chen (2016) the advantage of subject AF (or key word AF) is that it reflects the most current terminology in a particular subject given by the authors on their own words. Chen further emphasizes the possibility of getting current information through keyword searching. Understanding such importance, the OUSL library specifically maintains the SAF (keyword index) controlled vocabulary more than the other two files stated above.

This is how a topic is recorded in the SAF. As class numbers represent subjects, in addition to that other relevant specific additional key words are included to the database entry with the hope of creating more access points.

\section{E.g. 340 -Law \\ 341- International law \\ 580 - Zoology}

Subject headings/terms (Key words) or (topics) for each number are given by using the classification scheme (DDC $23^{\text {rd }}$ edition). Although, subjects are analyzed in the DDC, subject headings are prepared using the list of subject headings. The Library of Congress Subject Heading (LCSH) list is used to generate key words and access points.

E.g.:- an entry with keywords.

\subsection{Gunasekera, Danapala}

GUN Basic cataloguing: a guide for trainers/Danapala Gunasekera. $-3^{\text {rd }}$ ed...-Colombo: NLDSB, 2004.

vii, 242p.Fig. $21 \mathrm{~cm}$

ISBN: 9558383260

\section{i. Cataloguing ii. Library science}

Altogether five access points are available in the above entry (author, title, class number, first and second key words.).

The OUSL library prepares the unique subject heading which guides users to all relevant information including related or collocated subjects. Additional key words are added to the entry making more access points in addition to the topic as given in above example (Topic (main key word which tallies with class number) Cataloguing, library science is additional keyword). Only the main key word which tallies with class number is recorded in the subject authority file. Additional key words should be created by the cataloguer. For that cataloguer should have metadata creation skills and professional skills which is achieved by the experiences. More examples for the subject headings that are used in the OUSL library catalogue which are recorded in SAF are given as annexure. Subject heading list is prepared and developed in that manner while developing other authority files and maintaining authority control. 


\section{Consistency of the Entries of OUSL Library}

With authority control, one unique preferred name represents all variations and will include different variations, spellings and misspellings, uppercase versus lowercase variants.

\section{Recording when there is Prefix}

How names are written in the OUSL library entries when there is prefix: Especially, French names have prefixes 'de'. Instruction given in the authority card is 'class directly under the name of the author not under the prefix 'de'.

E.g. Maupasant or Balzac not De Maupasant or De Balzac

But OUSL follows different patterns when Sri Lankan names are written as De Silva, Manel; De Seram, Nimal.

In that way name authority cards are prepared when decisions are made time to time and are linked and indexed alphabetically in order to create efficient Name Authority File.

Further, examples are given below for how to maintain consistency when doing vocabulary control in the OUSL library:

\section{Adding Country Number to the Class Number}

The OUSL library SAF instructs the cataloguer in this way. 'Do not use country number in an entry when cataloguing Sri Lankan books. Use key word 'Sri Lanka' instead of the country number.

E.g. Economic development in Sri Lanka - class number is 330.9 and give 'Sri Lanka' as a key word without adding country number (5493) to the class number. Given key word is 'Economic development-Sri Lanka'.

But different rules are followed when classifying materials related to the other countries. The Subject AF states that country number should be added for other countries when building class numbers and key words too should be given.

See the examples given below.

i. 'Economic development in India' (330.954) -Economic development -India (key word)

ii. 'Economic development - USA' (330.973)- Economic development -USA (key word)

iii. 'Economic development - UK' (330.942 ) Economic development -UK (key word) 
Also there is a note in SAF 'use abbreviation when writing country name' in records (E.g. UK for United Kingdom).

\section{How to Catalogue Biographies,}

Two options are given in DDC system to classify biographies. Biographies can be placed under subject like Biographies-scientists (500.92), Biographies -Social scientists (300.92), Biographies -lawyers (340.92). The other option is all biographies can be placed in 920 area without placing them under each subject. The OUSL library uses the second option and all biographies are catalogued in 920 and rested all in one place in a book shelf. Hence, there is a note in the authority file stating 'all biographies and autobiographies should be classified under the 920'. In that manner the OUSL library maintains the consistency in the library catalogue.

\section{Conclusion and Suggestions}

The separate index is often referred to as an "authority file." It contains an indexable record of all decisions made by cataloguers in a given library which cataloguers consult when making, or revising, decisions about headings. The Librarian/cataloguer is the most responsible person in building authority files because it is a decisionmaking process and it deficits the ways vocabulary controlling is done. It shows professional abilities, skills and knowledge of the librarian. As a result, the records contain documentation about sources used to establish a particular preferred heading, and may contain information discovered while researching the heading which may be useful.

The objective of the article is to share cataloguing experiences among professionals in the LIS field. The answers for the first question, 'What are the best practices followed by OUSL Main library in authority control' was achieved. Hence the main objective has been achieved.

The article documents further, how materials are analyzed to understand the 'aboutness' of the materials and further to create metadata by the OUSL professionals. Therefore, the answer for the second question 'How OUSL create metadata analyzing subjects' was also found and the second objective has also been achieved from the findings.

The article describes how OUSL library maintains an efficient and effective catalogue by updating AFs and maintaining authority control in cataloguing to suit the digital era. Three types of AFs are maintained in the library while more emphasis is given for the maintenance of subject authority file through vocabulary control. Therefore, answer for the third question, 'How OUSL maintains the authority files' has also been achieved. 
Further, effective subject retrieval is currently done not only by the OPACs but also from bibliographic databases, full text systems, digital archives and the Internet. It attempts to project the nature of subject analysis systems requirements into the future and to draw some conclusions about what new information professionals should be taught, and what skills they need to acquire to develop and operate subject analysis systems into the next century. Finally, it also challenges information professionals to seize the opportunity and to take responsibility for subject analysis in retrieval of information now and into the future. Therefore, it is most important to practise and improve subject analysis skills of each professional to face challenges in the future which will enable them to create effective information retrieval system for the users.

It was observed that there are no proper guidelines nationally available to be used for the future professionals. Each country is responsible for authority headings for its own personal and corporate authors. National authority lists are available in each country for everyone to use. E.g. HKCAN, Japan MARC Authority file, KOR MARC. IFLA and ALA emphasizes the importance of availability of proper guidelines and national authority list for a country and earnestly request the authorities to prepare such lists. Authority lists related to each country are uploaded to the IFLA website. But there is no list for Sri Lanka. However, the name authority list for authors was published in 2005 by the National Library and Documentation Services Board (NLDSB).

Hence it can be suggested that a set of guidelines for the maintenance of AC related to national authority list should be prepared. AC guidelines should be based on basic guidelines of the RDA as it is a national requirement in the digital era. In addition to the updated name authority list of Sri Lankan authors which was prepared by NLDSB, names of the monks and change of names of the authors and corporate are also suggested. LIS professionals should be educated on the maintenance of Authority files. LIS curricula should be changed to suit the digital environment.

\section{References}

American Library Association (1979). ALA Glossary, Chicago: ALA

Ali (ed.). (2006). ANE's encyclopedic dictionary of library and information science, New Delhi: Ane Book

Chan, L. M., Athena S. (2016). Cataloguing and classification: an introduction, $4^{\text {th }}$ ed., Lanham: Rowman \& Littlefield publishers

Denscombe, M. (2010). The good research guide for small scale research projects 4th ed., Buckingham: Open University Press.

Katru nama sadikari lekanaya (Sinhala) (2005). Colombo: National Library and Documentation Services Board 
Joudrey, D. N., Taylor, A.G. \& Miller, D. P. (2015). Introduction to cataloging and classification, California: Santa Barbara

Lankage, J. (1997). Modern technology and the digitization of Sinhala personal names in bibiliographies, catalogues, and databases: problems and solutions-a point of view, Library News, 18 (4) October-December, pp18-20.

Lankage, J. (2010). Sri Lankan authors: Buddhist monks' Sri Lanka Library Review, 24 June (2010), pp37- 41.

Lubetzky, S. (1953). Cataloguing rules and principles: a critique of the A.L.A rules for entry and a proposed design for their revision, Washington: Library of Congress

McNiff (2002). Action Research: Principles and Practice. London: Routledge. 


\section{Annex-1 List of subject heading (Topics)}

\section{Subject headings used for Buddhism}

\begin{tabular}{ll}
\hline 294.3 & - Buddhism \\
294.301 & - Buddhist philosophy \\
294.30103 & - Encyclopedias - Buddhist philosophy \\
294.3082 & - Buddhist women devotees \\
294.337 & - Buddhism - interreligious attitudes \\
294.34 & - Buddhist doctrines \\
294.34237 & - Rebirth
\end{tabular}

Subject headings used for Computer science

\begin{tabular}{ll}
\hline 004 & - Computer science \\
004.03 & - Dictionnaires - computer science \\
004.16 & - Micro computers \\
004.678 & - Internet \\
004.13 & - Programming languages \\
$004.13 \mathrm{~B}$ & - Programming language - BASIC
\end{tabular}

Subject headings used for Sinhalese literature

\begin{tabular}{ll}
\hline $\mathbf{8 9 1 . 4 8}$ & - Sinhalese literature \\
891.4803 & - Dictionaries - Sinhalese literature
\end{tabular}

891.481- Sinhalese poetry

$891.48103 \quad$ - Sinhalese narrative poetry

$891.48104 \quad$ - Sinhalese lyric poetry

891.482- Sinhalese drama

891.482025 - Sinhalese television drama

981.482081 - Sinhalese historical drama

891.483- Sinhalese fiction

$981.48301 \quad$ - Sinhalese short stories

981.483081 - Sinhalese historical stories

981.4830872 - Sinhalese detective fiction

981.48308762 - Sinhalese science fiction 